Acta technologica agriculturae 2

Nitra, Slovaca Universitas Agriculturae Nitriae, 2014, p. 29-34

\title{
RECOGNITION AND CLASSIFICATION OF PRODUCE AFFECTED BY IDENTICALLY LOOKING POWDERY MILDEW DISEASE
}

\author{
Jagadeesh D. PUJARI ${ }^{1}$, Rajesh YAKKUNDIMATH ${ }^{2 *}$, Abdulmunaf S. BYADGI ${ }^{3}$ \\ 'SDM College of Engineering and Technology, Dharwad, India \\ ${ }^{2} \mathrm{KLE}$ Institute of Technology, Hubli, India \\ ${ }^{3}$ University of Agricultural Sciences, Dharwad, India
}

\begin{abstract}
Plant diseases are visually observable patterns of a particular plant. Varieties of plant diseases, which are recognized by human beings, are identical or look similar in appearance. In this paper, we have considered recognition of fungal disease symptom like powdery mildew, looking similar in appearance affected on different produce. The powdery mildew symptom affected on produce like grape, mango, chili, wheat, beans and sunflower are considered for classification. Colour and texture features are extracted from image samples of produce affected by powdery mildew symptom. The extracted features are then used as inputs to knowledge-based and artificial neural network (ANN) classifiers and tests are performed to classify image samples. The colour analysis is done using Red, Green, Blue (RGB) and Hue, Saturation, Intensity (HSI) models. Texture analysis is done using gray level co-occurrence matrix (GLCM). The overall average classification accuracy with colour, texture and combined features are $70.48 \%$, $70.07 \%$ and $76.61 \%$ respectively using the ANN classifier. The overall average classification accuracy has increased to $71.92 \%$, $80.60 \%$ and $87.80 \%$ with colour, texture and combined features respectively using the knowledge-based classifier.
\end{abstract}

Keywords: plant disease, powdery mildew, feature extraction, knowledge base, artificial neural network

Crop cultivation depends on rainfall, quality of the soil and climatic conditions, short of any one of these leads to loss of crop. Diseases are major for loss of crop and really a challenge to control the diseases. Most of the plants diseases are caused by fungus, bacteria, viruses, etc. Plant disease diagnosis is an art as well as science. The diagnostic process (i.e. recognition of symptoms and signs) is inherently visual and requires intuitive judgment as well as the use of scientific methods. Photographic images of symptoms and signs of plant diseases used extensively to enhance description of plant diseases are invaluable in research, teaching and diagnostics, etc. Plant pathologists can incorporate these digital images using digital image transfer tools in diagnosis of plant diseases.

Farmers are very much concerned about the huge costs involved in these activities and severe loss. The cost intensity, automatic correct identification and classification of diseases based on their particular symptoms are very useful to farmers and also agriculture scientists. Early detection of diseases is a major challenge in horticulture/agriculture science. Development of proper methodology is certainly of use in these areas. Many diseases produce symptoms, which are the main indicators in field diagnosis. But plant disease detection is at most need for farmers. Due to natural calamities and diseases, we incur losses amounting to few crores every year. Early detection will help farmers to avoid huge loss. As such, several important decisions regarding safe practices, the production and processing of plants have been made in the recent past. Technology support would help them in this aspect by cutting on cost of pesticides. One of the main concerns of scientists is the automatic disease diagnosis and control. Computer vision systems would help to tackle the problem (Pujari et al., 2013b).

To know the state-of-the-art in automation of tasks/ activities in agricultural field and recognition of plant diseases using machine vision techniques, a survey is made. The gist of the survey carried out is given as follows.

Barbedo (2013) presented a survey on methods that use digital image processing techniques to detect, quantify and classify plant diseases from digital images in the visible spectrum. The selected proposals are divided into three classes according to their objective: detection, severity quantification, and classification. Bandi et al. (2013) proposed machine vision and image processing techniques in sleuthing the disease mark in citrus leaves. Citrus leaves were investigated using texture analysis based on colour co-occurrence matrix (CCM) and classified using various classifiers. Dubey et al. (2012) proposed image processingbased approach to evaluate diseases of apple. Local binary features were extracted from the segmented image, and finally images were classified using a multi-class support vector machine (SVM). Guru et al. (2011) have presented a novel algorithm for extracting lesion area and application of neural network to classify tobacco seedling diseases. First order statistical texture features were extracted from lesion area and probabilistic neural network (PNN) is employed to classify anthracnose and frog-eye spots present on tobacco seedling leaves. Al-Hiary et al. (2011) have evaluated a software solution for automatic detection and classification of plant leaf diseases. The affected area was segmented and texture analysis was done using CCM. Neural network classifier was used to classify various plant diseases. Sankaran et al. (2010) reviewed advanced techniques for detecting plant diseases. Some of the non-invasive techniques have been used for plant disease detection. The two major categories for non-invasive monitoring of plant diseases, namely spectroscopic and imaging techniques and volatile organic compounds profiling-based technique, were used for recognizing plant diseases. Rumpf et al. (2010) 

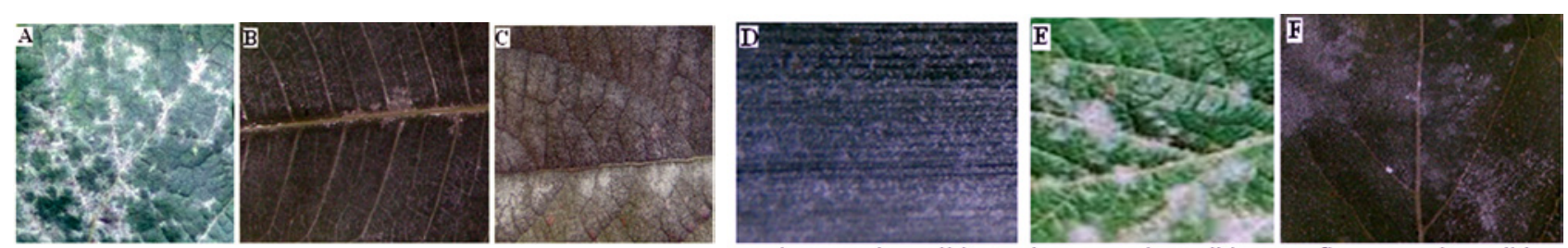

Figure 1

Visual powdery mildew symptom affected on: (A) grape, (B) mango, (C) chili, (D) wheat, (E) beans, (F) sunflower

proposed automatic methods for an early detection of plant diseases are vital for precision crop protection. The main contribution of this paper is a procedure for the early detection and differentiation of sugar beet diseases based on SVM and spectral vegetation indices. Cui et al. (2010) report research outcomes from developing image processing methods for quantitatively detecting soybean rust severity from multi-spectral images. To achieve automatic rust detection, an alternative method of analyzing the centroid of leaf colour distribution in the polar coordinate system was investigated. Leaf images with various levels of rust severity were collected and analyzed. Kim et al. (2009) investigated the potential of using colour texture features for detecting citrus peel diseases. Classification models were constructed using the reduced texture feature sets through discriminant function based on the measure of generalized squared distance. Boissard et al. (2008) have presented a cognitive vision system that combines image processing, learning and knowledge-based techniques in early disease detection in crops. Huang (2007) has presented an application of neural network and image processing techniques for detecting and classifying phalaenopsis seedling diseases. The texture features using gray level co-occurrence matrix (GLCM) and colour features were used in the classification procedure. Back propagation neural network (BPNN) classifier was employed to classify phalaenopsis seedlings diseases. Pydipati et al. (2006) have used computer vision and image processing techniques in the early detection and classification of diseased citrus leaves from normal citrus leaves. The colour texture feature using CCM was used as an input to various classifiers.

From the literature survey it reveals that machine vision has the potential to become a viable tool to identify disease type. Although several image processing approaches have been presented for detection of plant diseases, no attempts are made for recognition of identically looking disease symptoms affected on different types of agriculture/ horticulture produce. There are several disease symptoms looking identical and similar in appearance like rust, leaf spot, anthracnose, powdery mildew, etc. on the affected produce. Due to unavailability of sufficient number of data sets, we have limited the present work only to the recognition of identically looking powdery mildew symptom. In this paper, we have developed a methodology using image processing techniques for determining the type of produce affected by identically looking powdery mildew symptom.

Powdery mildew (Blumeria graminis) is considered one of the most common, easily recognized fungal disease symptoms. The disease is most commonly observed on upper sides of leaves. It also affects the bottom sides of leaves, young stems, buds, flowers and young fruit. Powdery mildews are

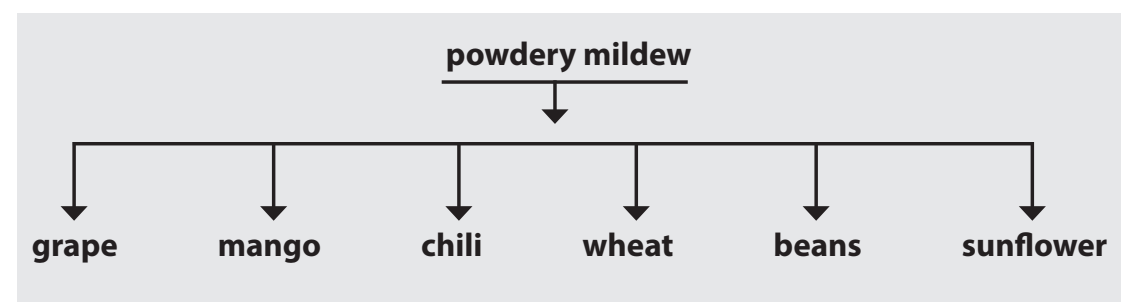

Figure 2 Classification tree

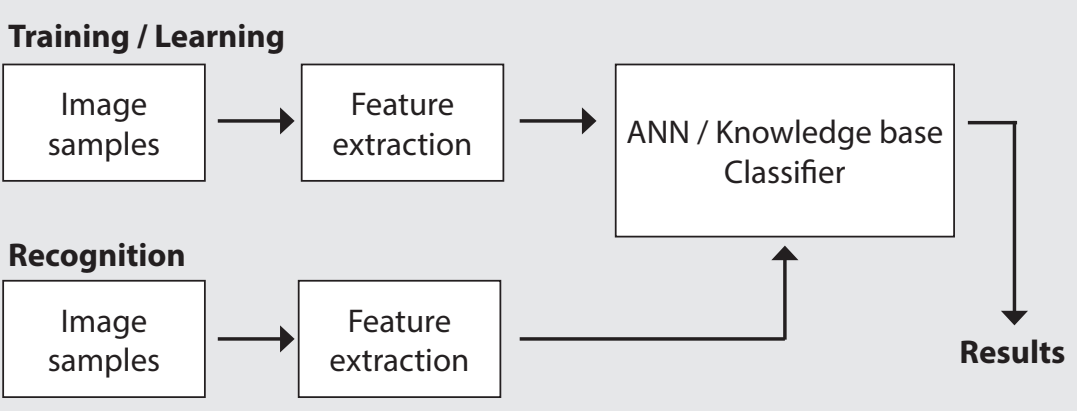

Figure 3 Block diagram of proposed methodology characterized by spots or patches of white to grayish, talcum-powder like growth. Powdery mildew symptom affects wide range of plants. In the present work, we have considered powdery mildew symptom affected on produce like grape (Vitis vinifera), mango (Mangifera indica), chili (Capsicum annuum), wheat (Triticum), beans (Phaseolus vulgaris), and sunflower (Helianthus annuus). The sample images of produce affected by powdery mildew symptom are shown in Figure1.

The paper is organized into four sections. Section 2 gives the proposed methodology. Section 3 describes results and discussion. Section 4 gives conclusion of the work.

\section{Material and methods}

In the present work, tasks like image acquisition, pre-processing, feature extraction, and classification are carried out. The classification tree is given in Figure 2. The detailed block diagram of adopted methodology is shown in Figure 3. 


\section{Image set}

We have considered image samples of produce affected by powdery mildew symptom like grape powdery mildew (Uncinula necator), mango powdery mildew (Oidium mangiferae), chili powdery mildew (Leveillula taurica), wheat powdery mildew (Blumeria graminis f. sp. tritici), beans powdery mildew (Erysiphe polygoni), and sunflower powdery mildew (Golovinomyces cichoracearum) for the study. The image samples were obtained from the Department of Plant Pathology at the University of Agricultural Sciences, Dharwad, India. In the present work, powdery mildew symptom affected on leaves considered as the first signs and symptoms appears on leaves and ambiguity in recognition is more on leaves compared to other parts of plants.

\section{Image acquisition and pre-processing}

The single powdery mildew affected image is captured by digital camera. For image acquisition, a colour camera (DXC-3000A, Sony, Tokyo, Japan) was used. The camera has a zoom lens of $10-120 \mathrm{~mm}$ focal length and a $72 \mathrm{~mm}$ close-up lens set. The camera is vertically oriented and approximately a distance of 0.5 meter is maintained while capturing the images. The images are acquired after 7 days of the first appearance of powdery mildew symptom on leaves. The quality of the image is decisive for the results of analysis, affecting both the ability to detect features under analysis and precision of subsequent measurements. To improve the quality of the image, pre-processing steps are applied over image. The pre-processing of image includes shade correction, removing artifacts and formatting. Some images, primarily from digital cameras, exhibit irregular illumination, called shade. Some regions are brighter and some others are darker than the mean value for the whole image. This phenomenon is a consequence of inaccuracy in the system and first of all due to an uncontrollable lightning conditions. Precise tuning of camera is done to minimize this effect. The images contain some artifacts induced like scratches, smearing, relief, pull-outs, comet tails or lapping tracks. We have used median filter to remove such artifacts. Formatting deals with storage representation and setting the attributes of the image. The images acquired from the camera are of $1920 \times 1080$ pixels and are reduced to a $400 \times$ 300 size for the reasons of reducing computational time required for features extraction and their storage on the medium.

\section{Feature extraction}

Human beings recognize objects in the real world by the visual features such as colour, size, shape, and texture. From the images shown in Figure 1, we find that the image samples of powdery mildew symptom affected on produce look similar. This task is challenging when we wish to deploy automation. Hence, in this work, we have used both colour and texture features for image analysis. Colour features are extracted using RGB and HSI colour models. Texture features are extracted using the gray level co-occurrence matrix (GLCM) method. We have used a total of 18 colour features and 24 texture features which are extracted from the images of produce affected by powdery mildew symptom (Pujari et al., 2013a, 2013b)

\section{Classifiers}

We have adopted knowledge-based and artificial neural network (ANN) classifiers in the recognition and classification of images of produce affected by powdery mildew symptom.

\section{Knowledge-based classification}

The knowledge base is a collection of rules or other information structure derived from human expert. The major components of any knowledge-based classifier are identified as a fact base and an inference engine. The fact base and rule base combine to form a knowledge base and form the kernel of any knowledge-based classifier. The block schematic view of a typical knowledge-based system is shown in Figure 4.

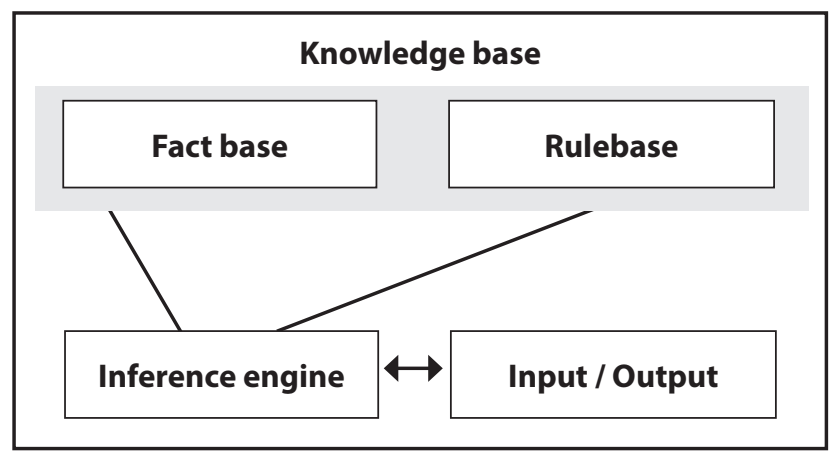

Figure 4 Kernel of knowledge-based system

The features extracted from images are stored in the knowledge base. Typically, the rules are in the form of if/ then statements. A number of related rules collectively correspond to an inference, which leads from some initially known facts to some useful considerations. The minimum and maximum values of each of the colour and texture features are used as knowledge during classification of image samples for colour and texture features. The process adopted for classification is given by Algorithms 1 \& 2 . The abbreviations used in the rules are F1: red mean, F2: red range, F3: red variance, F4: green mean, F5: green range, F6: green variance, F7: blue mean, F8: blue range, F9: blue variance, F10: hue mean, F11: hue range, F12: hue variance, F13: saturation mean, F14: saturation range, F15: saturation variance, F16: intensity mean, F17: intensity range, F18: intensity variance, F19: red CM mean, F20: red CM variance, F21: red CM range, F22: red CM energy, F23: red CM MP, F24: red CM contrast, F25: red CM IDM, F26: red CM correlation, F27: green CM mean, F28: green CM variance, F29: green CM range, F30: green CM energy, F31: green CM MP, F32: green CM contrast, F33: green CM IDM, F34: green CM correlation, F35: blue CM mean, F36: blue CM variance, F37: blue CM range, F38: blue CM energy, F39: blue CM MP, F40: blue CM contrast, F41: blue CM IDM, F42: blue CM correlation, GPD: grape powdery mildew, MPD: mango powdery mildew, CPD: chili powdery mildew, WPD: wheat powdery mildew, BPD: beans powdery mildew, SPD: sunflower powdery mildew.

Algorithm 1: Recognition and classification of image samples using colour features

Input: Values of F1 to F18

Output: Recognized and classified images 


\section{Start}

Step 1: if (FiGPDMin $<=F i<=F i G P D M a x)$ for $i=1$ to 18 then

declare sample_type = grape powdery mildew and stop.

Step 2: if (FiMPDMin $<=$ Fi<=FiMPDMax) for $i=1$ to 18 then

declare sample_type $=$ mango powdery mildew and stop.

Step 3: if (FiCPDMin $<=F i<=F i C P D M a x)$ for $i=1$ to 18

then

declare sample_type $=$ chili powdery mildew and stop.

Step 4: if (FiWPDMin $<=F i<=F i W P D M a x)$ for $i=1$ to 18

then

declare sample_type $=$ wheat powdery mildew and stop.

Step 5: if (FiBPDMin $<=F i<=F i B P D M a x)$ for $i=1$ to 18

then

declare sample_type $=$ beans powdery mildew and stop.

Step 6: if (FiSPDMin $<=F i<=F i S P D M a x)$ for $i=1$ to 18

then

declare sample_type $=$ sunflower powdery mildew and stop.

Stop.

Algorithm 2: Recognition and classification of image samples using texture features

Input: Values of F19 to F42

Output: Recognized and classified images

Start

Step 1: if (FiGPDMin $<=F i<=F i G P D M a x)$ for $\mathrm{i}=19$ to 42

then

declare sample_type $=$ grape powdery mildew and stop.

Step 2: if (FiMPDMin<=Fi<=FiMPDMax) for $\mathrm{i}=19$ to 42

then

declare sample_type $=$ mango powdery mildew and stop.

Step 3: if (FiCPDMin $<=F i<=F i C P D M a x)$ for $i=19$ to 42

then

declare sample_type $=$ chili powdery mildew and stop.

Step 4: if (FiWPDMin $<=F i<=$ FiWPDMax) for $\mathrm{i}=19$ to 42

then

declare sample_type $=$ wheat powdery mildew and stop.

Step 5: if (FiBPDMin $<=F i<=F i B P D M a x)$ for $i=19$ to 42

then

declare sample_type $=$ beans powdery mildew and stop.

Step 6: if (FiSPDMin $<=F i<=F i S P D M a x)$ for $i=19$ to 42

then

declare sample_type $=$ sunflower powdery mildew and stop.

Stop.

\section{Artificial neural network-based classification}

In order to corroborate the accuracy of classification obtained from knowledge-based classifier, we have considered a multilayer back propagation neural network (BPNN) as an alternate model to recognize the produce affected by powdery mildew symptom. We have used six output nodes and forty two input nodes corresponding to six chosen categories of produce affected by powdery mildew symptom and chosen forty two features respectively. We have used sigmoid activation functions in the hidden layers. The number of nodes in the hidden layer is calculated using Equation (1).

$$
n=\frac{(I+O)}{2}+y \wedge 0.5
$$

where:

$n \quad$ - number of nodes in hidden layer

I - number of inputs feature

O - number of outputs

$y \quad$ - number of inputs pattern in the training set

The steps involved in recognition and classification of image samples using knowledge-based and artificial neural network (ANN) classifiers is given in Algorithm 3 .

Algorithm 3: Recognition and classification of image samples

Input: Images of produce affected by powdery mildew symptom

Output: Recognized and classified images

\section{Start}

Step 1: Collect the images of produce affected by powdery mildew symptom

Step 2: Extract different colour and texture features

Step 3: Train the knowledge-based and BPNN with extracted features

Step 4: Collect test images and perform step 2

Step 5: Recognize and classify the images using knowledgebased and BPNN

Stop.

\section{Results and discussion}

All the algorithms used in this work are implemented using MATLAB 7.10. The image samples are divided into two halves and one half is used for training and other is for testing. The percentage of recognition and classification accuracy is defined as the ratio of correctly recognized image samples to the total number of test image samples. The percentage accuracy is calculated as given by Equation (2).

Percentage accuracy $(\%)=$

$$
\frac{\text { correctly recognized image samplex }}{\text { total number of test image samples }} \times 100
$$

We have considered 600 image samples ( 100 samples of each type). We trained with 300 samples (50 images of each type) and tested with remaining 300 samples. The training and testing are carried out with colour and texture features. 


\section{Classification accuracy using knowledge-based classifier}

The classification results with colour, texture and combined features using knowledge-based classifier are given in Table 1. The individual average classification accuracy of grape powdery mildew, mango powdery mildew, chili powdery mildew, wheat powdery mildew, beans powdery mildew and sunflower powdery mildew are $70.53 \%$, $75.44 \%, 80.50 \%, 66.90 \%, 54 \%$ and $84.17 \%$ respectively using colour features. The individual average classification accuracy of grape powdery mildew, mango powdery mildew, chili powdery mildew, wheat powdery mildew, beans powdery mildew and sunflower powdery mildew are $79.34 \%, 82.60 \%, 89.21 \%, 76.33 \%, 65.50 \%$ and $90.60 \%$ respectively using texture features. The individual average classification accuracy of grape powdery mildew, mango powdery mildew, chili powdery mildew, wheat powdery mildew, beans powdery mildew and sunflower powdery mildew are $81.42 \%, 92 \%, 92.17 \%, 80.90 \%, 86 \%$ and $94.30 \%$ respectively using combined features. The overall average classification accuracy using colour, texture and combined features are $71.92 \%, 80.60 \%$ and $87.80 \%$ respectively.

\section{Classification accuracy using ANN classifier}

The classification results with colour, texture and combined features using ANN classifier are given in Table 2. The individual average classification accuracy of grape powdery mildew, mango powdery mildew, chili powdery mildew, wheat powdery mildew, beans powdery mildew and sunflower powdery mildew are $60.21 \%, 78.52 \%, 53.14 \%$, $80.70 \%, 66.93 \%$ and $83.40 \%$ respectively using colour features.

The individual average classification accuracy of grape powdery mildew, mango powdery mildew, chili powdery mildew, wheat powdery mildew, beans powdery mildew and sunflower powdery mildew are $63.13 \%, 76.38 \%$, $55.46 \%, 83.70 \%, 60.40 \%$ and $81.39 \%$ respectively using texture features. The individual average classification accuracy of grape powdery mildew, mango powdery mildew, chili powdery mildew, wheat powdery mildew, beans powdery mildew and sunflower powdery mildew are $74.50 \%, 80.29 \%, 59.20 \%, 84.72 \%, 73.50 \%$ and $87.48 \%$ respectively using combined features. The overall average classification accuracy using colour, texture and combined features are $70.48 \%, 70.07 \%$ and $76.61 \%$ respectively.

\section{Comparison of knowledge-based and artificia neural network classifiers}

We have compared the recognition accuracies obtained using knowledge-based and neural network-based classifiers for different images of produce affected by powdery mildew symptom. Table 3 gives the performance

Table 1 Classification accuracy using knowledge-based classifier

\begin{tabular}{|l||c|c|c|c|c|c|c|}
\hline \multirow{2}{*}{ Features } & \multicolumn{9}{|c|}{ Powdery mildew disease } \\
\cline { 2 - 8 } & $\begin{array}{c}\text { grape powdery } \\
\text { mildew }\end{array}$ & $\begin{array}{c}\text { mango powdery } \\
\text { mildew }\end{array}$ & $\begin{array}{c}\text { chili powdery } \\
\text { mildew }\end{array}$ & $\begin{array}{c}\text { wheat powdery } \\
\text { mildew }\end{array}$ & $\begin{array}{c}\text { beans powdery } \\
\text { mildew }\end{array}$ & $\begin{array}{c}\text { sunflower } \\
\text { powdery mildew }\end{array}$ & $\begin{array}{c}\text { average } \\
\text { in \% }\end{array}$ \\
\hline \hline Colour & 70.53 & 75.44 & 80.50 & 66.90 & 54.00 & 84.17 & 71.92 \\
\hline Texture & 79.34 & 82.60 & 89.21 & 76.33 & 65.50 & 90.60 & 80.60 \\
\hline $\begin{array}{l}\text { Combined } \\
\text { colour \& } \\
\text { texture }\end{array}$ & 81.42 & 92.00 & 92.17 & 80.90 & 86.00 & 94.30 & 87.80 \\
\hline
\end{tabular}

Table 2 Classification accuracy using ANN classifier

\begin{tabular}{|l||c|c|c|c|c|c|c|}
\hline \multirow{2}{*}{ Features } & \multicolumn{9}{c|}{ Powdery mildew disease } \\
\cline { 2 - 9 } & $\begin{array}{c}\text { grape powdery } \\
\text { mildew }\end{array}$ & $\begin{array}{c}\text { mango powdery } \\
\text { mildew }\end{array}$ & $\begin{array}{c}\text { chili powdery } \\
\text { mildew }\end{array}$ & $\begin{array}{c}\text { wheat powdery } \\
\text { mildew }\end{array}$ & $\begin{array}{c}\text { beans powdery } \\
\text { mildew }\end{array}$ & $\begin{array}{c}\text { sunflower } \\
\text { powdery mildew }\end{array}$ & $\begin{array}{c}\text { average } \\
\text { in \% }\end{array}$ \\
\hline \hline Colour & 60.21 & 78.52 & 53.14 & 80.70 & 66.93 & 83.40 & 70.48 \\
\hline Texture & 63.13 & 76.38 & 55.46 & 83.70 & 60.40 & 81.39 & 70.07 \\
\hline $\begin{array}{l}\text { Combined } \\
\text { colour \& } \\
\text { texture }\end{array}$ & 74.50 & 80.29 & 59.20 & 84.72 & 73.50 & 87.48 & 76.61 \\
\hline
\end{tabular}

Table 3 Classification results of identical powdery mildew disease symptom affected on produce

\begin{tabular}{|c|c|c|c|c|c|c|}
\hline \multirow{3}{*}{ Features } & \multicolumn{6}{|c|}{ Classifiers } \\
\hline & \multicolumn{3}{|c|}{ knowledge-based } & \multicolumn{3}{|c|}{ ANN } \\
\hline & $\begin{array}{c}\text { minimum classification } \\
\text { accuracy in } \%\end{array}$ & $\begin{array}{c}\text { maximum classification } \\
\text { accuracy in } \%\end{array}$ & $\begin{array}{c}\text { average } \\
\text { in } \%\end{array}$ & $\begin{array}{c}\text { minimum classification } \\
\text { accuracy in \% }\end{array}$ & $\begin{array}{c}\text { maximum classification } \\
\text { accuracy in } \%\end{array}$ & $\begin{array}{c}\text { average } \\
\text { in } \%\end{array}$ \\
\hline Colour & 54.00 & 84.17 & 69.085 & 53.14 & 83.40 & 68.27 \\
\hline Texture & 65.50 & 90.60 & 78.050 & 55.46 & 83.70 & 69.58 \\
\hline $\begin{array}{l}\text { Combined } \\
\text { colour \& } \\
\text { texture }\end{array}$ & 80.90 & 94.30 & 87.6 & 59.20 & 87.48 & 73.34 \\
\hline
\end{tabular}


evaluation of both knowledge-based and ANN classifiers. From Table 3, the maximum classification accuracy of $84.17 \%, 90.60 \%$ and $94.30 \%$ is observed with colour, texture and combined features respectively using knowledge-based classifier. The minimum classification accuracy of $54 \%, 65.50$ $\%$ and $80.90 \%$ is observed with colour, texture and combined features using knowledge-based classifier. The maximum classification accuracy of $83.40 \% 83.70 \%$ and $87.48 \%$ is observed with colour, texture and combined features respectively using ANN classifier. The minimum classification accuracy of $53.14 \% 55.46 \%$ and $59.20 \%$ is observed with colour, texture and combined features using ANN classifier.

It is observed that the accuracies using knowledge-based classifier are better than ANN. It is also observed that reduction in recognition using colour and texture features for both classifiers is due to the maximum overlap of the colour and texture features of powdery mildew symptom on different produce. With the combined colour and texture features, we have observed an increase in recognition and classification accuracies. The experimental results have shown that the combined colour and texture features using knowledge base are more suitable for recognition and classification of produce affected by identically looking powdery mildew symptom.

\section{Conclusion}

In this paper, we have discussed the different approaches to recognize the identically looking powdery mildew symptom affected on agriculture/horticulture produce. The combination of colour and texture features is suitable for recognition and classification of produce affected by identically looking powdery mildew symptom. Compared to ANN, knowledge-based classifier has given better recognition and classification accuracy.

However, there is still scope for improvement in recognition accuracies using further different neural network architectures, support vector machine (SVM), fuzzybased classifiers. We can extend this work to classify visual symptoms affected by disease symptoms on different types of vegetables, commercial crops, cereals, fruits. The work can also be extended to identify various diseases like viral, bacterial, etc. affected on agriculture/horticulture produce.

\section{Acknowledgment}

We would like to express our thanks to Dr. B. S. Anami, principal, KLE Institute of Technology, for his valuable suggestions.

\section{References}

AL-HIARY, H. - BANI-AHMAD, S. - REYALAT, M. - BRAIK, M. ALRAHAMNEH, Z. 2011. Fast and accurate detection and classification of plant diseases. In International Journal of Computer Applications, vol. 17, 2011. no. 1, pp. 31-38.

BANDI, S.R. - VARADHARAJAN, A. - CHINNASAMY, A. 2013. Performance evaluation of various statistical classifiers in detecting the diseased citrus leaves. In International Journal of Engineering Science and Technology, vol. 5, 2013. no. 2, pp. 298-307.

BARBEDO, J.C.A. 2013. Digital image processing techniques for detecting, quantifying and classifying plant diseases. In Springer Plus, 2013, no. 2, p. 660.
BAUER, S.D. - FILIP, K. - WOLFGANG, F. 2011. The potential of automatic methods of classification to identify leaf diseases from multispectral images. In Precision Agriculture, vol. 12, 2011. no. 3, pp. 361-377.

BOISSARD, P. - MARTIN, V. - MOISAN, S. 2008. A cognitive vision approach to early pest detection in greenhouse crops. In Computers and Electronics in Agriculture, vol. 62, 2008. no. 2, pp. 81-93.

CUI, D. - ZHANG, Q. - LI, M. - HARTMAN, G.L. - ZHAO, Y. 2010. Image processing methods for quantitatively detecting soybean rust from multispectral images. In Biosystems Engineering, vol. 107, 2010. no. 3, pp. 186-193.

DUBEY, S.R. - JALAL, A.S. 2012. Adapted approach for fruit disease identification using images. In International Journal of Computer Vision and Image Processing, vol. 2, 2012. no. 3, pp. 51-65.

DUDA, R.O. - HART, P.E. - STORK, D.G. 2000. Pattern classification. Third edition. John Wiley \& Sons.

GONZALEZ, R.C. - WOODS, R.E - EDDINS, S.L. 2009. Digital image processing using MATLAB. Second edition. Addison-Wesley Publishing Company.

GURU, D.S. - MALLIKARJUNA, A.B. - MANJUNATH, S. 2011. Segmentation and classification of tobacco seedling diseases. In COMPUTE, 11 Proceedings of the Fourth Annual ACM. Bangalore.

HUANG, K.Y. 2007. Application of artificial neural network for detecting Phalaenopsis seedling diseases using color and texture features. In Computers and Electronics in Agriculture, vol. 57, 2007. no. 1, pp. 3-11.

KIM, D.G. - BURKS, T.F. - QIN, Z. - BULANON, D.M. 2009. Classification of grapefruit peel diseases using color texture feature analysis. In International Journal of Agricultural \& Biological Engineering, vol. 2, 2009. no. 3, pp. 41-50.

PATIL, J.K. - KUMAR, R. 2011. Advances in image processing for detection of plant diseases. In Journal of Advanced Bioinformatics Applications and Research, vol. 2, 2011. no. 2, pp. 135-141.

PUJARI, J.D. - YAKKUNDIMATH, R. - BYADGI, A.S. 2013a. Reduced color and texture features based identification and classification of affected and normal fruits' images. In International Journal of Agricultural and Food Science, vol. 3, 2013. no. 3, pp. 119-127.

PUJARI, J.D. - YAKKUNDIMATH, R. - BYADGI, A.S. 2013b. Statistical methods for quantitatively detecting fungal disease from fruits' images. In International Journal of Intelligent Systems and Applications in Engineering, vol. 1, 2013. no. 4, pp. 60-67.

PYDIPATI, R. - BURKS, T.F. - LEE, W.S. 2006. Identification of citrus disease using color texture features and discriminate analysis. In Computers and Electronics in Agriculture, vol. 52, 2006. pp. 49-59. RUMPF, T. - MAHLEIN, A.K. - STEINER, U. - OERKE, E.C. - DEHNE, H.W. - PLUMER, H. 2010. Early detection and classification of plant diseases with Support Vector Machines based on hyperspectral reflectance. In Computers and Electronics in Agriculture, vol. 74, 2010. no. 1, pp. 91-99.

SANKARAN, S. - MISHRA, A. - EHSANI, R. - DAVIS, C. 2010. A review of advanced techniques for detecting plant diseases. In Computers and Electronics in Agriculture, vol. 72, 2010. no. 1, pp. 1-13.

SONKA, M. - HLAVAC, V. - BOYLE, R. 2008. Digital image processing and computer vision. Third edition. Cengage Learning.

YAO, Q. - GUAN, Z. - ZHOU, Y. - TANG, J. - HU, Y. - YANG, B. 2009. Application of support vector machine for detecting rice diseases using shape and color texture features. In International Conference on Engineering Computation.

\section{Contact address:}

Rajesh Yakkundimath*, KLE Institute of Technology, Hubli 580 030, India, e-mail: rajeshymath@gmail.com 